\title{
Crystal Engineering of Fe" Spin Crossover Coordination Polymers Derived from Triazole or Tetrazole Ligands
}

\author{
Yann Garcia*, N. N. Adarsh, and Anil D. Naik
}

\begin{abstract}
The past decade has witnessed intense research activity in the area of Fe"l spin crossover coordination polymers, which are structurally diverse and functionally intriguing materials. In this endeavor, a less exploited series of ligands have been selected among various $\mathrm{N}$-donor triazole and tetrazole molecules. Developing conventions that allow the tailoring of such functional materials with predictable architecture and properties is an important objective and current interest in crystal engineering. However, detailed knowledge on the structureproperty correlation is still scanty due to the small number of crystal structures of such compounds. The principal focus is to decipher the effect of various supramolecular factors such as intermolecular interactions, hydrogen bonding etc., on the resultant Fell coordination polymers. This tutorial review aims at highlighting some of the developments of such structurally diverse and functionally intriguing 1D polymeric chains, 2D and 3D networks built from triazole or tetrazole ligands exhibiting fascinating spin crossover phenomena.
\end{abstract}

Keywords: Iron(II) coordination polymers · Metal organic frameworks · Molecular bistability · Spin crossover

\section{Introduction}

There are currently an increasing number of reports describing the crystal structures of coordination polymers (CPs) and metal-organic frameworks (MOFs). ${ }^{[1,2]}$ Despite the variety of architectures and dimensionalities, CPs with functional properties that can be tailored are rare. There exists however an exciting class of materials, exhibiting spin crossover (SCO) phenomena, which could be used to probe the impact of intermolecular contacts and ligand design in the crystalline state. Their synthesis is a challenge in supramolecular chemistry, ${ }^{[3]}$ crystal engineering ${ }^{[4]}$ and materials science because of the various factors which affect the resultant structural-dependent SCO property such as the nature of the solvent used for the synthesis/crystallization, the ligand, the anion, lattice defects, etc. While a few examples of $\mathrm{Fe}^{\mathrm{III}}$ and $\mathrm{Co}^{\mathrm{II}} \mathrm{SCO}$ CPs have been communicated, ${ }^{[5-8]}$ efforts have focused on $\mathrm{Fe}^{\mathrm{II}}$ polymeric materials. Most of these materials incorporate multidentate $N$-donor heterocyclic bridging ligands such as 1,2,4-

${ }^{*}$ Correspondence: Prof. Dr. Y. Garcia Institute of Condensed Matter and Nanosciences (MOST)

Université Catholique de Louvain

Place L. Pasteur 1

1348 Louvain-la-Neuve, Belgium

E-mail: yann.garcia@uclouvain.be or 1,2,3-triazole, $1-R$ or 2- $R$-tetrazole, polypyridine-like derivatives, or tetra-, di-cyanometallate, polynitrile anions and tetradentate Schiff bases (Fig. 1). [9]

On cooling, these CPs usually exhibit thermally induced gradual spin conversions. In certain cases, abrupt spin transitions with hysteresis effects, whose width strongly depends on the nature of the molecular bridge between $\mathrm{Fe}^{\mathrm{II}}$ sites as well as on crystal packing, are observed. The $\mathrm{Fe}^{\mathrm{II}} \mathrm{SCO}$ phenomenon involves an entropy driven intra-ionic electron transfer from a diamagnetic low-spin (LS) state to a paramagnetic high-spin (HS) state which is reversibly induced by external stimuli like temperature, pressure and light irradiation etc. ${ }^{[10]}$ A chromic effect may occur as a result of the change of electronic structure. This change is remarkable for
$\mathrm{Fe}^{\mathrm{II}}$ complexes with azole ligands, making materials of this substance class attractive for practical applications, e.g. as switching devices and sensors. ${ }^{[11]}$ In this review, we discuss prototype materials as well as highlight recent examples of $\mathrm{Fe}^{\mathrm{II}} \mathrm{CPs}$ and/or MOFs constructed from ligands based on organic ligands such as triazole/ tetrazole and poly-triazole/tetrazole. The journey takes us from one-dimensional (1D) chains to two-dimensional (2D) and three-dimensional (3D) SCO networks and MOFs.

\section{D Chain Compounds}

4R-1,2,4-triazole-based $\quad \mathrm{Fe}^{\mathrm{II}}$ chain compounds have been widely studied, due to their potential for practical applications

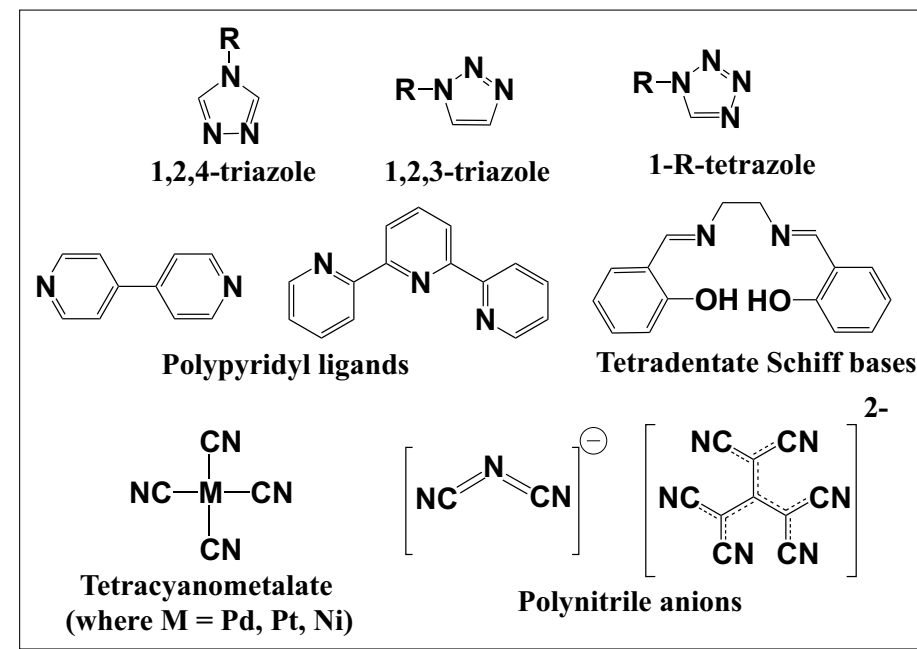

Fig. 1. Building blocks for crystal engineering $\mathrm{Fe}^{\prime \prime}$ spin crossover coordination polymers (where $\mathrm{R}=\mathrm{H}$ or any functional group).

Tetracyanometalate (where $\mathrm{M}=\mathbf{P d}, \mathbf{P t}, \mathrm{Ni}$ )
Polynitrile anions 
(memory devices, displays, sensors, cold/ hot channels tracking, ....). ${ }^{[11,12]}$ These materials are currently the body of intense miniaturization efforts as well as used as components of hybrid materials. ${ }^{[13]}[\mathrm{Fe}(4-$ $R$-1,2,4-triazole $\left.)_{3}\right] \mathrm{A}_{2} \cdot$ Solv $(\mathrm{A}=$ counter anion and Solv $=$ solvent molecules included in the lattice) are made up of linear chains in which the adjacent $\mathrm{Fe}^{\mathrm{II}}$ ions are linked by three $N 1, N 2-1,2,4$-triazole ligands and spaced out $c a$. $3.6 \AA$, as concluded by detailed EXAFS investigations at the $\mathrm{Fe}-\mathrm{K}$ edge ${ }^{[14]}$ and a recent $\mathrm{X}$-ray diffraction study of a LS material (Fig. 2).[15] In the solid state, these $1 \mathrm{D}$ chain compounds generally exhibit a SCO phenomenon accompanied by a hysteresis width of flexible magnitude, sometimes centered at room temperature. ${ }^{[16]}$ In these materials, the coordination linker represented by the 1,2,4-triazole building block is sufficiently rigid to allow an efficient transmission of cooperative effects leading to hysteresis loops of width ranging from $\sim 2-20 \mathrm{~K} .{ }^{[17]}$

Thus strengthening of intra-molecular interactions by triple 1,2,4-triazole bridges connecting spin changing molecules can promote cooperative effects, which result in the observation of a wide range of hysteresis widths. ${ }^{[17]}$ Intermolecular interactions also contribute to the SCO cooperative mechanism, thus resulting in larger hysteresis loops. Such intermolecular interactions can be propagated through supramolecular interactions involving noncoordinated counter-anions and solvent molecules (most often water), which are localized between or within the chains. ${ }^{[17]}$ As a result, only three ' $1 \mathrm{D}$ chains' display exceptional SCO properties with an hysteresis width of $\sim 35-50 \mathrm{~K}$. This is the case for $\left[\mathrm{Fe}(\mathrm{Htrz})_{2}(\operatorname{trz})\right] \mathrm{BF}_{4}(\mathrm{Htrz}=$ 4-H-1,2,4-triazole, trz = triazolato), whose synthesis was first reported in 1977 by Haasnoot, ${ }^{[18]}$ and which displays a SCO above room temperature with a hysteresis width of $\sim 35 \mathrm{~K} \cdot{ }^{[19]}$ In this material, two types of interchain interactions were identified both by wide angle X-ray scattering ${ }^{[20]}$ and Rietveld refinements of powder X-ray diffraction data:[21] direct through Htrz-trz contacts and indirect through $\mathrm{N}-\mathrm{H}^{\cdots} \mathrm{BF}_{4} \cdots \mathrm{H}-\mathrm{N}$ linkages where the nitrogen atoms occupy the 4-position of the triazole ligands. Another example concerns the $1 \mathrm{D}$ chain $[\mathrm{Fe} \text { (hyptrz) })_{3}$ (4-chloro3-nitrophenylsulfonate) ${ }_{2} \cdot \mathrm{H}_{2} \mathrm{O}(\mathbf{1})$ (hyptrz $=$ 4-(3'-hydroxypropyl)-1,2,4-triazole) that displays a characteristic hysteresis width of $\sim 50 \mathrm{~K}$ below room temperature, ${ }^{[22]}$ and for which $\pi-\pi$ stacking interactions involving the aromatic anions as well as direct H-bonding between the 4- $R$ substituent of neighboring chains were detected in the crystal structure of the analogous $\mathrm{Cu}^{\mathrm{II}}$ (Fig. 3). Its exceptional bistability domain allowed the linearity of chains in both

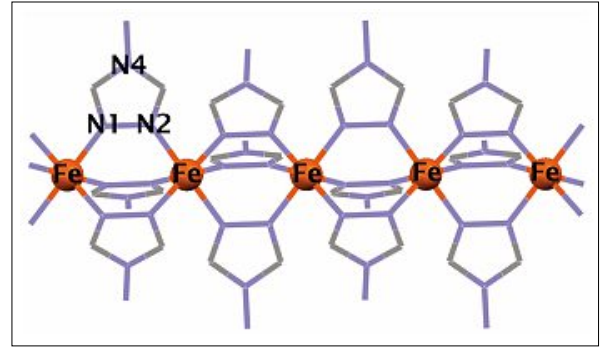

Fig. 2. View of the crystal structure of the 1D LS chain of [Fe(4-amino-1,2,4-triazole) $\left.{ }_{3}\right]$ $\left(\mathrm{NO}_{3}\right)_{2} \cdot \mathrm{H}_{2} \mathrm{O} \cdot{ }^{[15]}$ propagation of elastic interactions through the network (Fig. 4). ${ }^{[25]}$

[Fe(1,2-bis(tetrazol-1-yl)propane) $\left.{ }_{3}\right]$ $\left(\mathrm{ClO}_{4}\right)_{2}(4)$ is the first SCO chain whose crystal structure has been determined by single crystal X-ray diffraction, both in the HS and LS states. [26] The extended coordination of the ligand 1,2-bis(tetrazol-1-yl) propane, resulted in a looped chain coordination polymer, with $\mathrm{Fe} \cdot . \mathrm{Fe}$ distances of $\sim 7.3 \AA$. Non-coordinated perchlorate anions occupy the interstitial space of
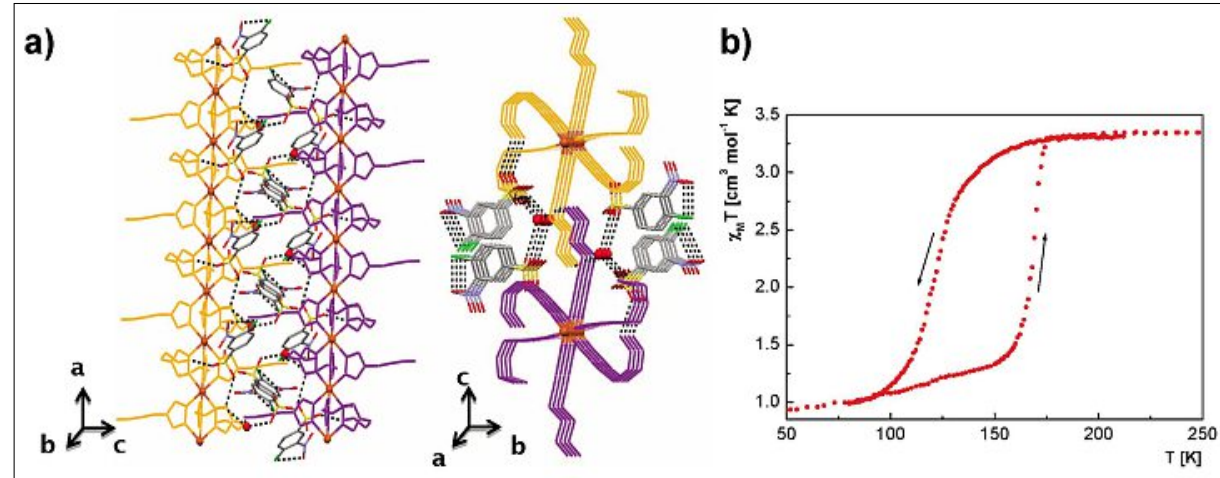

Fig. 3. a) Crystal structure illustration of $\mathrm{Cu}^{\text {ll }}$ analogous of 1; the polymeric chains are shown with orange and purple colour and the 4-chloro-3-nitrophenylsulfonate counter anion and lattice included water molecules are occluded within the interstitial space of the chains sustained by various $\mathrm{H}$-bonding interactions (shown with black dotted lines); b) Temperature dependence of $\chi_{M} T$ for $\mathbf{1}$, in both cooling and warming modes. ${ }^{[22]}$

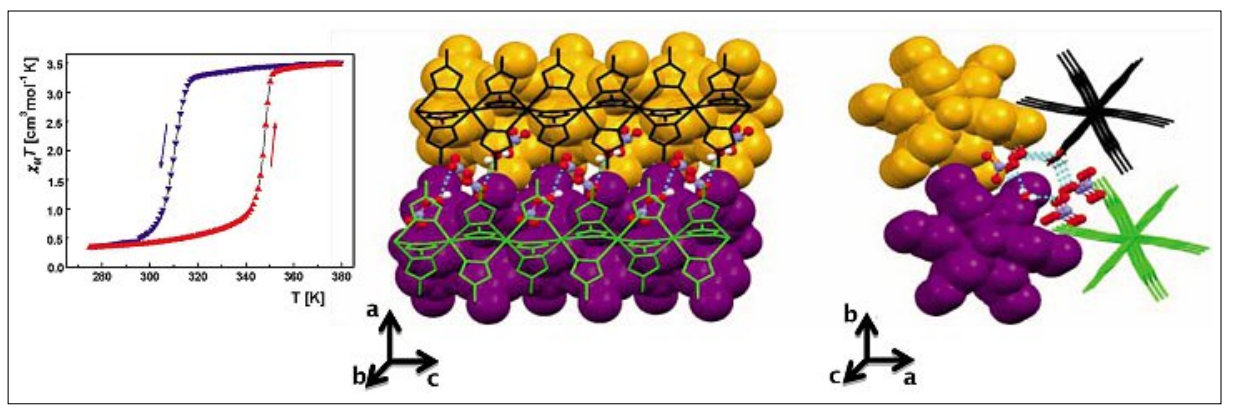

Fig. 4. (Left) Hysteretic ST slightly above the room temperature region for 2; (Right) Crystal packing of polymeric chains (shown in orange-black and purple-green colour) in 3 . H-bonding interaction of counter anion $\mathrm{NO}_{3}{ }^{-}$and lattice included water molecule with the 1D chain shown by cyan coloured dotted line. ${ }^{[24]}$

LS and HS states to be demonstrated by EXAFS spectroscopy. ${ }^{[22]}$

The third example concerns $\left[\mathrm{Fe}\left(\mathrm{NH}_{2} \text { trz }\right)_{3}\right]\left(\mathrm{NO}_{3}\right)_{2}\left(\mathrm{NH}_{2}\right.$ trz $=4$-amino1,2,4-triazole) (2), discovered in 1986 by Lavrenova, ${ }^{[23]}$ which also displays an hysteretic spin transition (ST) located slightly above the room-temperature region. The crystal structure analysis of the analogous compound of 2 , namely $\left[\mathrm{Cu}\left(\mathrm{NH}_{2} \mathrm{trz}\right)_{3}\right]$ $\left(\mathrm{NO}_{3}\right)_{2} \cdot \mathrm{H}_{2} \mathrm{O}(3)$, confirmed the $1 \mathrm{D}$ chain character. $^{[24]} \mathrm{A}$ dense H-bonding network with the nitrate counter anion involved in both intra-chain and inter-chain interactions was observed. Such a supramolecular network could be at the origin of the unusually large hysteresis loop displayed by $2(\Delta T=37 \mathrm{~K})$, as a result of an efficient the looped chains of CP 4 (Fig. 5), without any intermolecular interactions. Noncoordinated perchlorate anions occupy interstitial space (Fig. 5). Despite its polymeric nature, the spin conversion is very gradual. The quasi absence of cooperativity, also noted in the isostructural tetrafluoroborate derivative, has been attributed to the flexibility of the bridging coordination network, as well as the absence of intermolecular contacts between 1D chains that cannot transmit efficiently structural changes associated with the spin change within the crystal lattice (Fig. 5). This compound presents the LIESST (Light Induced Excited Spin State Trapping) effect, first discovered by Decurtins et al. on $\left[\mathrm{Fe}(1-\text { propyltetrazole })_{6}\right]\left(\mathrm{BF}_{4}\right)_{2},{ }^{[27]}$ which 
was observed for this substance class for the first time. ${ }^{[26]}$ A similar gradual SCO behavior was revealed for other $1 \mathrm{D} \mathrm{Fe}^{\mathrm{II}}$ chains with triply ${ }^{[28,29]}$ and doubly bridging bis-tetrazole ligands. ${ }^{[30]}$ The situation differs for $\left[\mathrm{Fe}(\mu \text {-btzmp })_{2}(\text { btzmp })_{2}\right]$ $\left(\mathrm{ClO}_{4}\right)_{2}$ (btzmp = 1,2-bis(tetrazol-1-yl)2-methylpropane) that displays a steep and hysteretic spin transition, partly attributed to an anion order/disorder phenomenon, ${ }^{31]}$ and for $\left[\mathrm{Fe}(3 \mathrm{ditz})_{3}\right]\left(\mathrm{BF}_{4}\right)_{2}$ (3ditz $=$ 1,3-bis(tetrazol-1-yl)propane) which features an abrupt ST at $T_{1 / 2}=159 \mathrm{~K}$, as a result of packing effects despite the use of a flexible bridging ligand. ${ }^{[32]}$ Nevertheless, other $1 \mathrm{D} \mathrm{Fe} \mathrm{Fe}^{\mathrm{II}}$ chains made of two bridges that cushion elastic interactions as a consequence of the volume change associated to $\mathrm{SCO}^{[33]}$ were also described. ${ }^{[34-37]}$ Noticeably, numerous examples of 1D chains made of flexible single bridge spacers present the same SCO behavior as noted for 1,2-bis(4-pyridyl)etha(e)ne, ${ }^{[38]}$ 4,4'-bpy, ${ }^{[39]}$ substituted triazine/pyrimidine, ${ }^{[36,40]}$ pyrazine, ${ }^{[41]}$ dca anions, ${ }^{[42]}$ and tcpd anions. ${ }^{[43]}$ Interestingly, their crystal structures reveal various intermolecular interactions and $\mathrm{H}$-bonding involving the counter anion and lattice included solvent molecules (Fig. 6), but their contribution is meaningless compared to the weak coordination link existing between $\mathrm{Fe}^{\mathrm{II}}$ centers. As a result, gradual spin conversions are observed.

\section{D and 3D Networks}

A crystal engineering strategy makes use of multidentate ligands (that are suitable for SCO) connected by spacers which increases the possibilities to increase the dimensionality from $1 \mathrm{D}$ to $2 \mathrm{D}$ and $3 \mathrm{D}$. These ligands can potentially coordinate several metals whereas the spacers can increase the degrees of liberty/flexibility of the coordinating groups in order to promote coordination in several directions. ${ }^{[44]}$ This approach is however quite risky as other coordinating components such as anions and solvent molecules can interfere, contrary to the more straightforward route working with negatively charged ligands $\left(e\right.$. . azolate $^{[45]}$ or cyano ligands $\left.{ }^{[46]}\right)$ that have indeed afforded a large variety of MOFs, which are discussed in specialized review papers.

$\left[\mathrm{Fe}(\mathrm{btr})_{2}(\mathrm{NCX})_{2}\right] \cdot \mathrm{H}_{2} \mathrm{O}$ (where btr $=$ 4,4'-bis-1,2,4-triazole and $\mathrm{X}=\mathrm{S}, \mathrm{Se}$ ) represent the first 2D ST compounds. ${ }^{[47,48]}$ Among the variety of physical investigations, it was possible to detect the first pressure-induced LS-to-HS transition for a $2 \mathrm{D}$ net for $\left.\left[\mathrm{Fe}(\mathrm{btr})_{2}(\mathrm{NCS})_{2}\right] \cdot \mathrm{H}_{2} \mathrm{O}(\mathbf{5}),{ }^{449 a}\right]$ by magnetic susceptibility measurements which was confirmed by EXAFS spectroscopy. ${ }^{[49 b]}$ This material displays on cooling

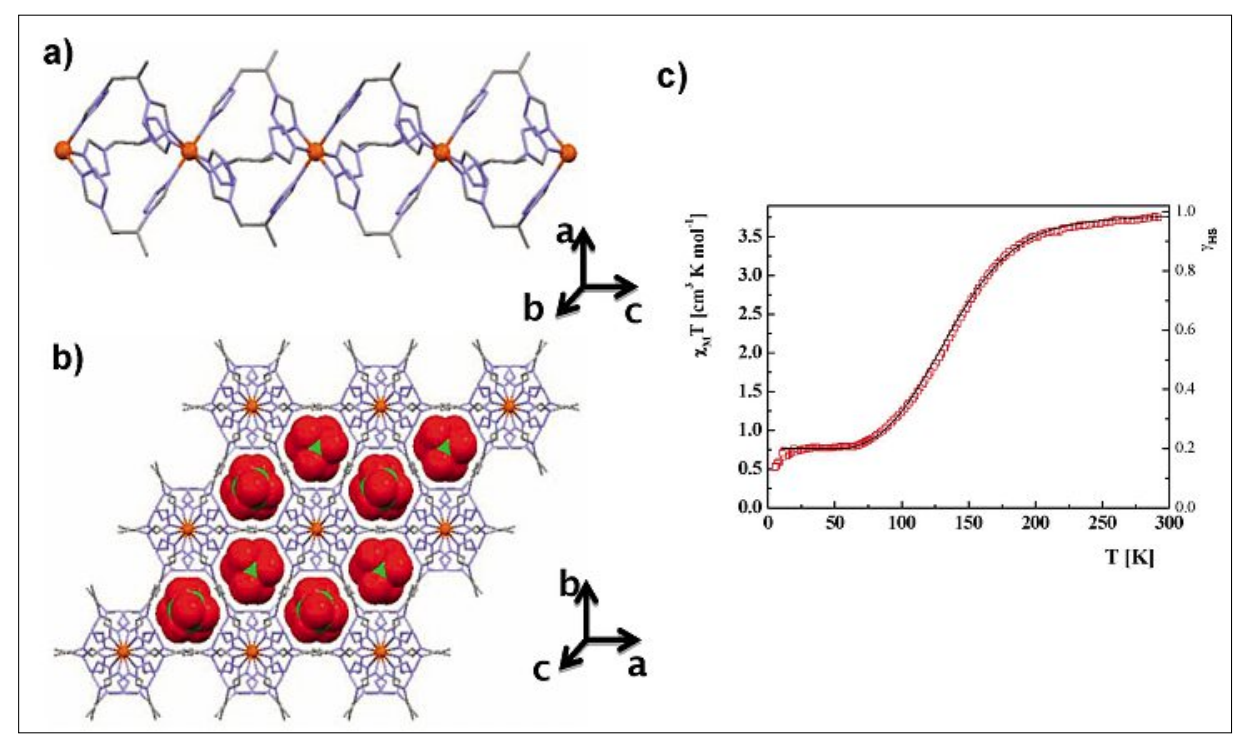

Fig. 5. Projection of the crystal structure of $\mathbf{4}$ along the $b$ axis showing a looped chain (a) and along the $c$ axis wherein the perchlorate counter anion (green-red) is occluded within the interstitial void of the chains (b); (c) $\chi_{M} T$ vs. T of $\mathbf{4}$ showing a gradual spin conversion, with a transition temperature $T_{1 / 2}=130 \mathrm{~K} \cdot{ }^{[26]}$

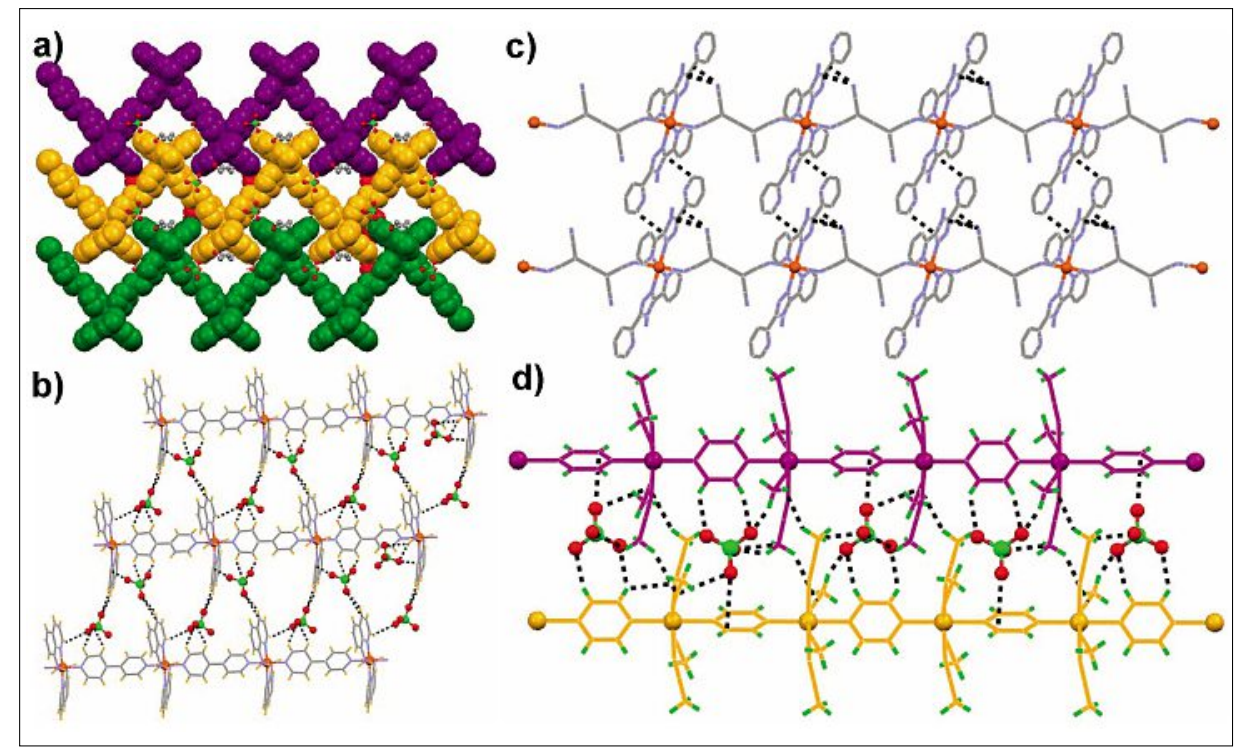

Fig. 6. Crystal structure illustration of linear CPs derived from various pyridyl ligands: a) Parallel packing of the $1 \mathrm{D}$ chains in $\left[\mathrm{Fe}(\text { pyim })_{2}(\mathrm{bpy})\right]\left(\mathrm{ClO}_{4}\right)_{2} \mathrm{C}_{2} \mathrm{H}_{5} \mathrm{OH}$ (pyim $=2$-(2-pyridyl)imidazole and bpy $=4,4$ '-bipyridine; distinct chains are shown with purple, orange and green colour) and the occluded ethanol and $\mathrm{ClO}_{4}^{-}$within the interstitial voids of the chains; ${ }^{[39]} \mathrm{b}$ ) inter-chain interaction in $\left[\mathrm{Fe}(\mathrm{aqin})_{2}(\mathrm{bpy})\right]\left(\mathrm{ClO}_{4}\right)_{2} \cdot 2 \mathrm{EtOH}$ (aqin = 8-amino-quinoline) via various weak interactions involving the counter anion $\mathrm{ClO}_{4}^{-}$and aromatic rings; $\left.{ }^{[39]} \mathrm{c}\right)$ Inter-chain interactions in [Fe(abpt) $\left.{ }_{2}(\mathrm{tcpd})\right]$ (where tcpd = 2-dicyanomethylene-1,1,3,3-tetracyanopropanediide anion, abpt $=4$-amino-3,5bis(pyridin-2-yl)-1,2,4-triazole) sustained by intra-chain $\mathrm{H}$-bonding and inter-chain $\pi \cdots \pi$ interactions; ${ }^{[43]}$ d) Inter-chain reorganization in $\left\{\left[\mathrm{Fe}\left(\mathrm{CH}_{3} \mathrm{CN}\right)_{4}(\text { pyrazine })\right]\left(\mathrm{ClO}_{4}\right)_{2}\right\}_{\mu}$ via various $\mathrm{H}$-bonding and anion $\cdots \pi$ interactions involving the $\mathrm{ClO}_{4}^{-}$counter anion and pyrazine. ${ }^{[4]}$

below room temperature a square shaped hysteresis loop of width $21 \mathrm{~K}$, associated to an extremely abrupt and complete thermally induced ST, free of any structural phase transition (Fig. 7d). Its crystal structure consists of $\mathrm{Fe}^{\mathrm{II}}$ ions linked by btr in two orthogonal directions establishing an infinite grid (Fig. 7a). The isothiocyanate anions, coordinated in trans position, prevent the formation of a 3D coordination network. The layers are connected by means of van der Waals forces and weak hydrogen bond bridges involving the water molecules, which are also $\mathrm{H}$-bonded to peripheral nitrogen atoms of the 1,2,4-triazole (Fig. 7b). Actually, the water molecule which is located between the layers (Fig. 7c), is crucial to maintain spin state switching conditions, and special care should be taken when studying this material. ${ }^{[47]}$ The Se derivative displays, as expected with the increase of ligand field strength, a ST at higher temperature but with a narrower hysteresis $(\sim 6 \mathrm{~K}) .{ }^{[48]}$ 
The crystal structure of $\left[\mathrm{Fe}(\mathrm{btre})_{2}(\mathrm{NCX})_{2}\right]$ (6) (where btre = 1,2-bis(1,2,4-triazol-4-yl)ethane and $\mathrm{X}=$ $\mathrm{S}, \mathrm{Se}$ ) reveals single type layers which are connected by a dense supramolecular network involving $\pi-\pi$ as well as inter-chalcogen interactions (Fig. 8). As a result, this too rigid network cannot be switched either by temperature, pressure (up to $\sim 12 \mathrm{kbar}$ ) or light irradiation (at $10 \mathrm{~K}) .^{[51]}$ This result represents a severe warning for supramolecular chemists: too many interactions can even quench SCO properties. A similar 2D ST grid was recently found for [Fe(baztrz) $($ pyz $\left.)(\mathrm{NCS})_{2}\right] \cdot 4 \mathrm{H}_{2} \mathrm{O}$ (baztrz $=$ trans $-4,4^{\prime}-$ azo-1,2,4-triazole) with the replacement of one bistriazole by pyrazine. ${ }^{[52]}$ Using only one bridging bis-tetrazole, instead of bis-triazole, afforded other 2D SCO grids displaying a less cooperative behavior. ${ }^{[53,54]}$

The first 2D grid constructed from a 1-R tetrazole was discovered for $\left[\mathrm{Fe}\left\{\mathrm{N}(\mathrm{entz})_{3}\right\}_{2}\right]\left(\mathrm{BF}_{4}\right)_{2}$ including the tripodal ligand, $\mathrm{N}(\mathrm{entz})_{3}=$ tris [2-(tetrazol-1-yl)ethyl]amine. ${ }^{[55]}$ This material displays an extremely abrupt ST with a thermal hysteresis width $\left(T_{1 / 2^{\dagger}}=176 \mathrm{~K}\right.$ and $T_{1 / 2^{\nu}}=167$ $\mathrm{K})$. Recently, a honeycomb-like pattern with cages occupied by disordered anions, was discovered for $\left[\mathrm{Fe}\left\{\mathrm{C}(\mathrm{mtz})_{3}\right\}_{2}\right] \mathrm{A}_{2},(\mathrm{~A}=$ $\left.\mathrm{ClO}_{4}^{-}, \mathrm{BF}_{4}^{-}\right)(7)$ built from another spiderlike ligand, $\mathrm{C}(\mathrm{mtz})_{3}=1,1^{\prime}, 1^{\prime \prime}$-tris(tetrazol1-ylmethyl)methane (Fig. 9). These 2D materials display a sharp ST at $T_{1 / 2}=$ $193 \mathrm{~K}\left(\mathrm{BF}_{4}^{-}\right)$and $T_{1 / 2}=176 \mathrm{~K}\left(\mathrm{ClO}_{4}^{-}\right) \cdot{ }^{[56]}$ $\left[\mathrm{Fe}(\operatorname{trptrz})_{2}\right]\left(\mathrm{BF}_{4}\right)_{2} \cdot 5 \mathrm{H}_{2} \mathrm{O}$ with trptrz $=$ tris-3-[1,2,4]triazol-4-yl-propyl phloroglucinol, which was obtained via a multistep synthesis involving a Mitsunobu coupling, is another example of 2D SCO CP based on a tripodal ligand. It reveals however a gradual spin conversion due to the flexible propyl group attached to the 1,2,4-triazole ligand that cushions elastic interactions between $\mathrm{Fe}^{\mathrm{II}}$ centers. ${ }^{[57]}\left[\mathrm{Fe}(\mathrm{bbtr})_{3}\right] \mathrm{A}, \mathrm{A}=$ $\mathrm{ClO}_{4}^{-},{ }^{-[58,59]} \mathrm{BF}_{4}{ }^{-[59,60]}$ (bbtr $=1,4-\operatorname{di}(1,2,3-$ triazol-1-yl)butane) are other 2D CPs with a $(3,6)$ network topology presenting an hexagonal sheet structure. While the perchlorate derivative displays an abrupt hysteretic ST around $100 \mathrm{~K}$, the tetrafluoroborate remains $\mathrm{HS}$ on cooling. Both materials are currently the topic of extensive optical investigations led by Hauser in Geneva.[61]

Very recently, thermally highly robust 2D neutral $\mathrm{Fe}^{\mathrm{II}}$ MOFs have been reported for $\left[\mathrm{FeL}_{2}\right]$ with $\mathrm{HL}=3$-(2-pyridyl)-5-(3pyridyl)-1,2,4-triazole or 3-(3-methyl2-pyridyl)-5-(3-pyridyl)-1,2,4-triazole. These materials display a two-step SCO at remarkably high temperatures for molecular materials (the highest step is above 500 $\mathrm{K}$ !), ${ }^{[62]}$ which could be good candidates for CVD deposition of thin films, as well as for high-temperature sensor applications.

$\left[\mathrm{Fe}(\mathrm{btr})_{3}\right]\left(\mathrm{ClO}_{4}\right)_{2} \quad(8)$ represents the

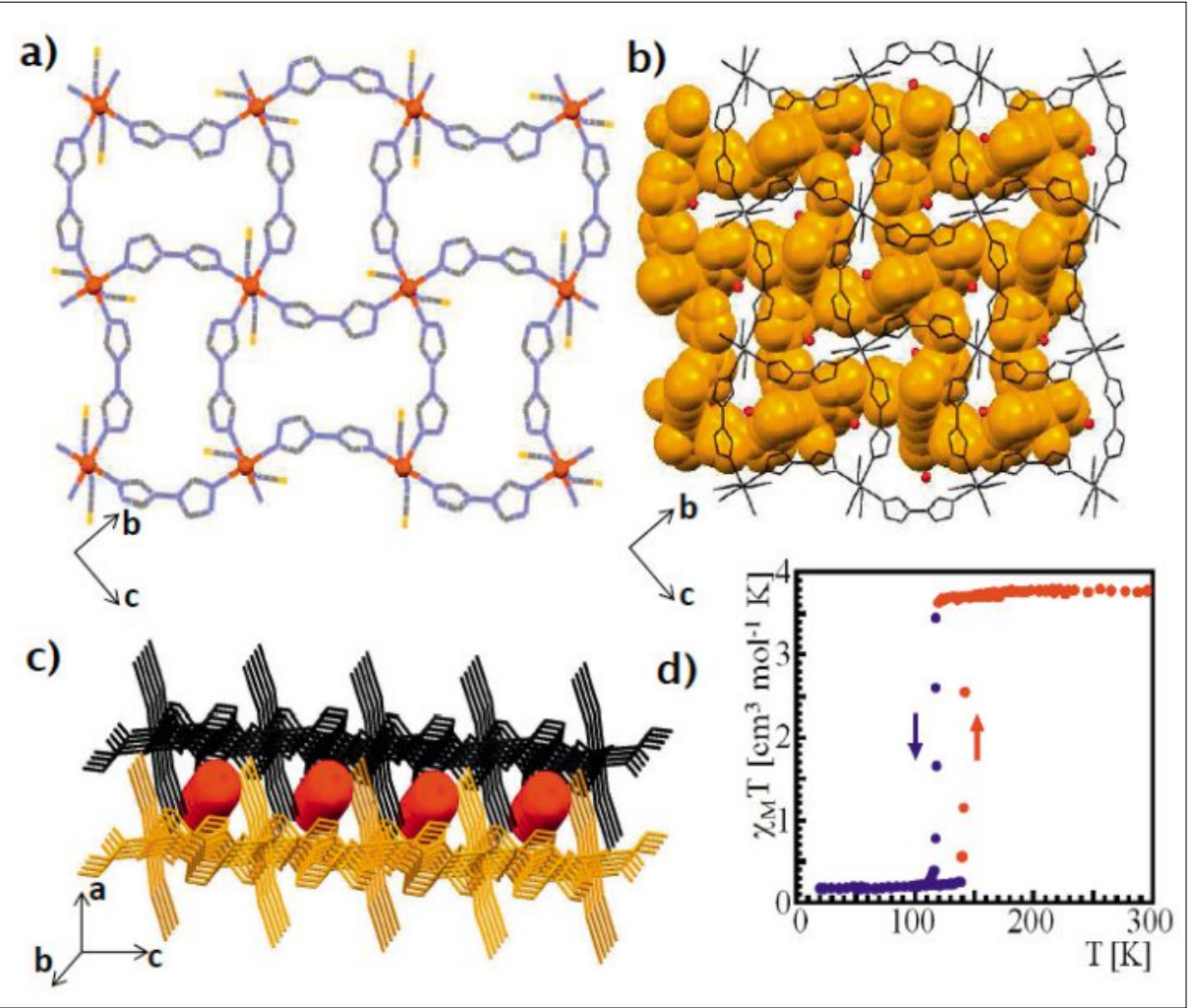

Fig. 7. a) View of the 2D layered structure of 5 at $293 \mathrm{~K}$; b) Off-set packed 2D layers (shown in orange and black colour) and lattice water molecules (red balls);[4]] $\mathrm{C}$ ) Non-coordinated water molecules (red spacefill) are located between sheets (orange and black); d) $\chi_{M} T$ vs. T plot showing a square-shaped hysteresis loop.

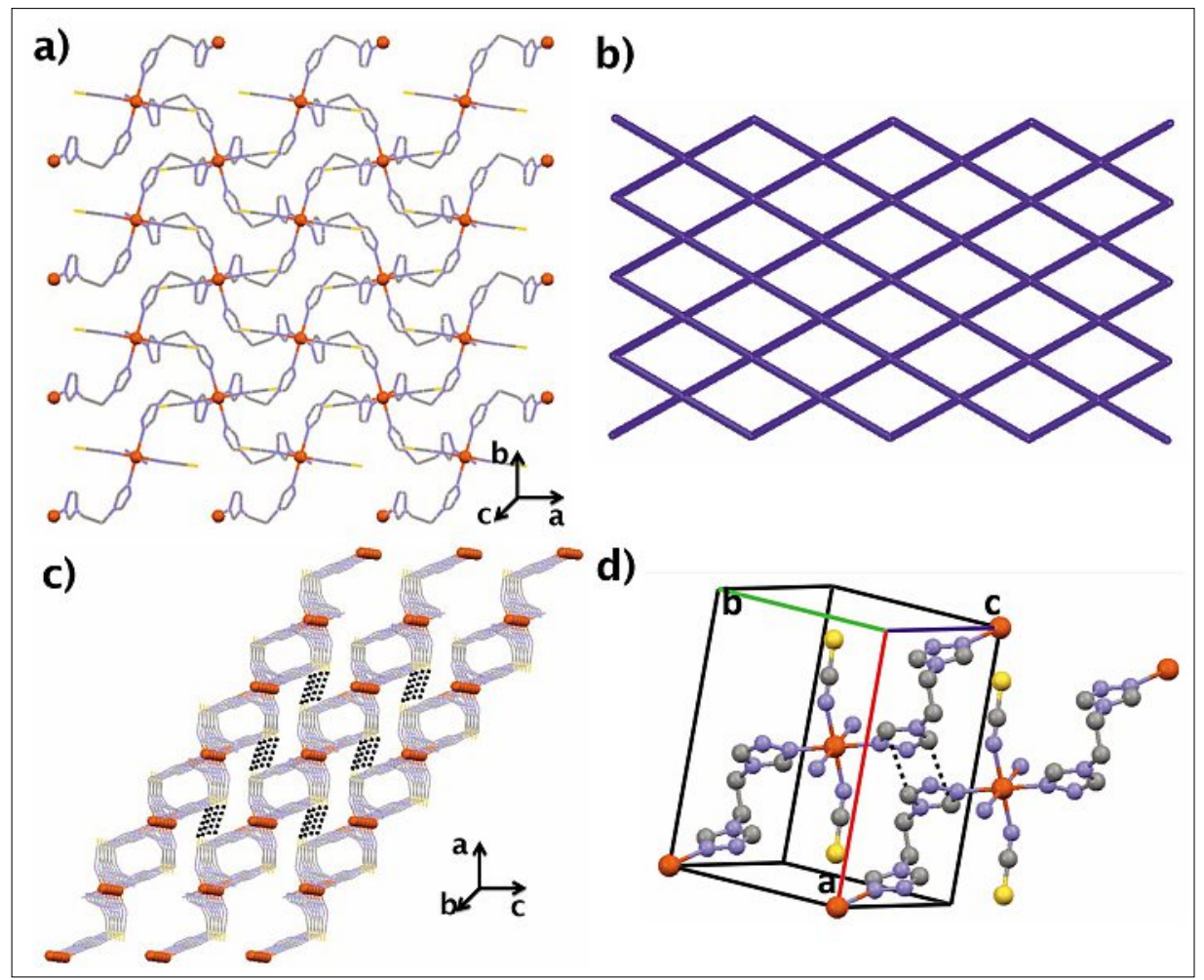

Fig. 8. a) 2D coordination polymer sheet of $\left[\mathrm{Fe}(\mathrm{btre})_{2}(\mathrm{NCS})_{2}\right]$. b) TOPOS ${ }^{[50]}$ view of the $2 \mathrm{D}$ sheet; c) inter-sheet $S \cdots S$ contacts. d) view of $\pi \cdots \pi$ interactions. ${ }^{[51]}$

first 3D SCO coordination polymer.[63] Its crystal structure consists of $\mathrm{Fe}^{\mathrm{II}}$ ions connected in $3 \mathrm{D}$ by bis-triazole ligands through the nitrogen atoms occupying the 1 and 1 ' positions, which leads to a pcu
alpha-Po primitive cubic topology (Fig. 10a,b). The non-coordinated perchlorate anions are located in the voids of the $3 \mathrm{D}$ architecture. Upon cooling, a double step $\mathrm{SCO}$ behavior is observed with a plateau 


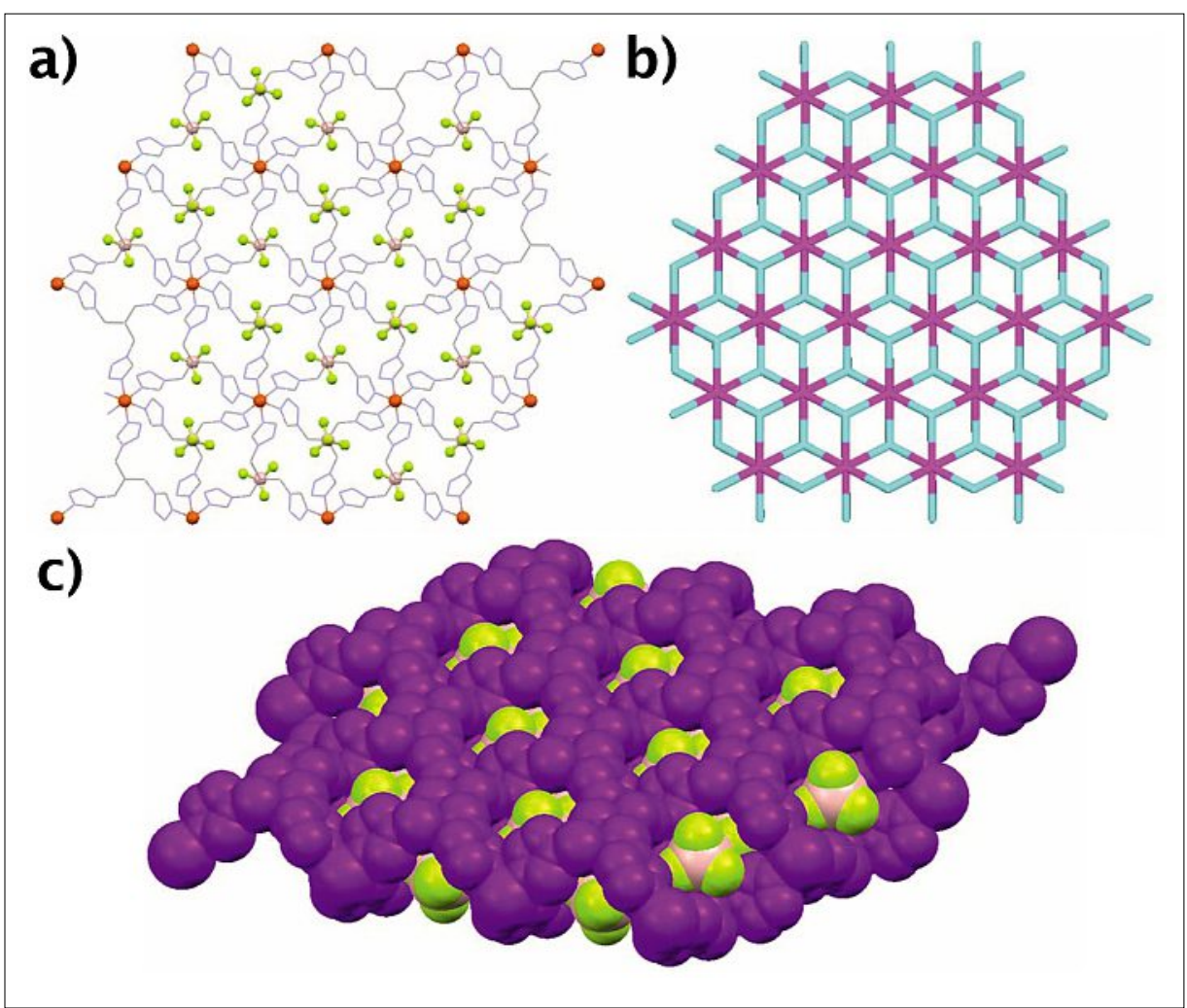

Fig. 9. Crystal structure of $\left[\mathrm{Fe}\left\{\mathrm{C}(\mathrm{mtz})_{3}\right\}_{2}\right]\left(\mathrm{BF}_{4}\right)_{2}$; a) $2 \mathrm{D}$ corrugated sheet like $\mathrm{CP}$ with a honeycomblike topology; b) TOPOS ${ }^{[50]}$ diagram of the $2 \mathrm{D}$ honeycomb network; c) occlusion of $\mathrm{BF}_{4}{ }^{-}$within the voids of 2D corrugated sheet (space-fill model with purple colour). ${ }^{[56]}$ at half conversion (Fig. 10c). A detailed single-crystal X-ray analysis together with temperature-dependent ${ }^{57} \mathrm{Fe}$ Mössbauer spectroscopy and magnetic susceptibility measurements have demonstrated that this additional step was due to a consecutive spin conversion occurring in two crystallographically inequivalent iron sites. ${ }^{[63]}$ The narrow hysteresis observed in the lower branch of the magnetic susceptibility curve (see inset of Fig. 10c), is free of any crystallographic phase transition, and is associated to a higher change of the dihedral angle $\delta$ between the 1,2,4-triazole moieties (from $\delta=79.72^{\circ}$ at $190 \mathrm{~K}$ in the plateau region to $\delta=87.17^{\circ}$ at $150 \mathrm{~K}$ in the LS state), compared to the higher branch of the SCO curve $\left(\delta=77.35^{\circ}\right.$ at $260 \mathrm{~K}$ in the HS state) that is smoother and not hysteretic (Fig. 10). A sufficient reorganization of the crystal lattice is thus necessary to allow a cooperative observation of the SCO behavior in the 3D lattice. A similar noninterpenetrated $3 \mathrm{D}$ polymeric architecture of pcu alpha-Po primitive cubic topology was observed for [Fe(1,3-bis(tetrazol-2-yl) propane $\left.)_{3}\right]\left(\mathrm{ClO}_{4}\right)_{2} \cdot 2 \mathrm{EtOH}(9)$. The guest perchlorate anion is found within the voids of the polymeric network sustained by various H-bonding interactions (Fig. 11).

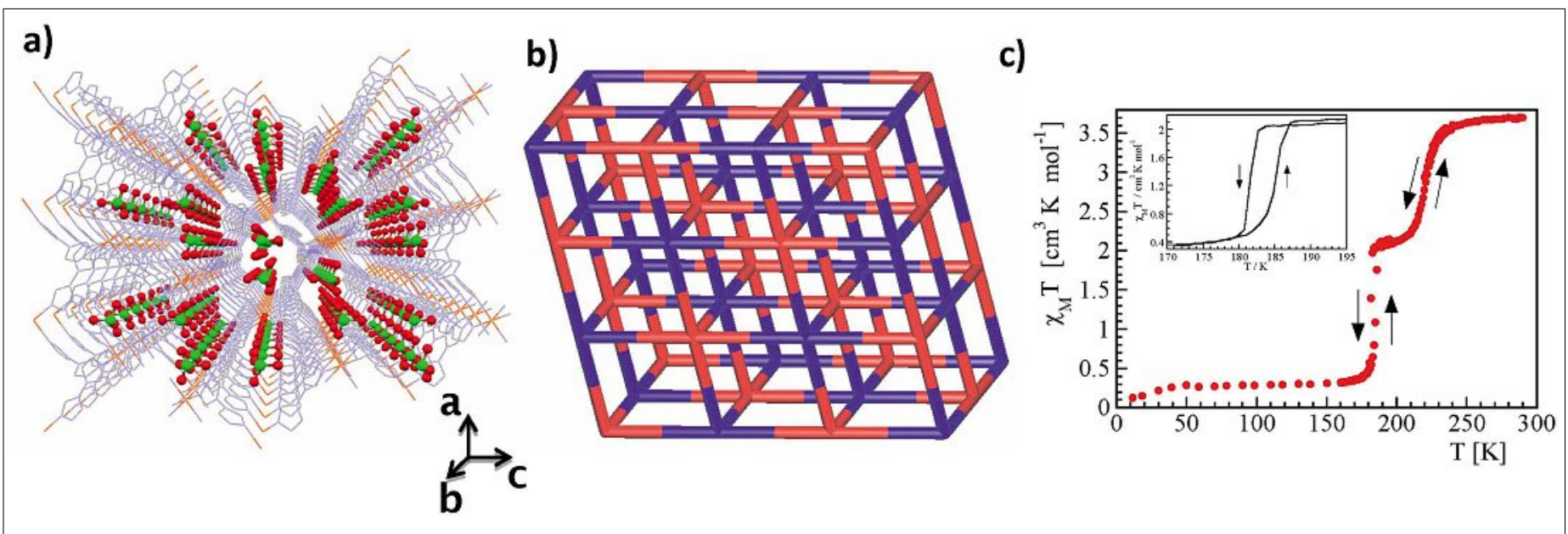

Fig. 10. a) 3D non-interpenetrated coordination polymeric structure of 8 displaying the entrapment of perchlorate anion within the cavity; b) TOPOS $^{[50]}$ view of the 3D coordination polymeric network of $\mathbf{8}$ with a pcu alpha-Po primitive cubic topology; c) $\chi_{M} T v s$. $T$ plot of 8 showing a twostep spin conversion. The inset reveals a hysteresis effect. ${ }^{[63]}$

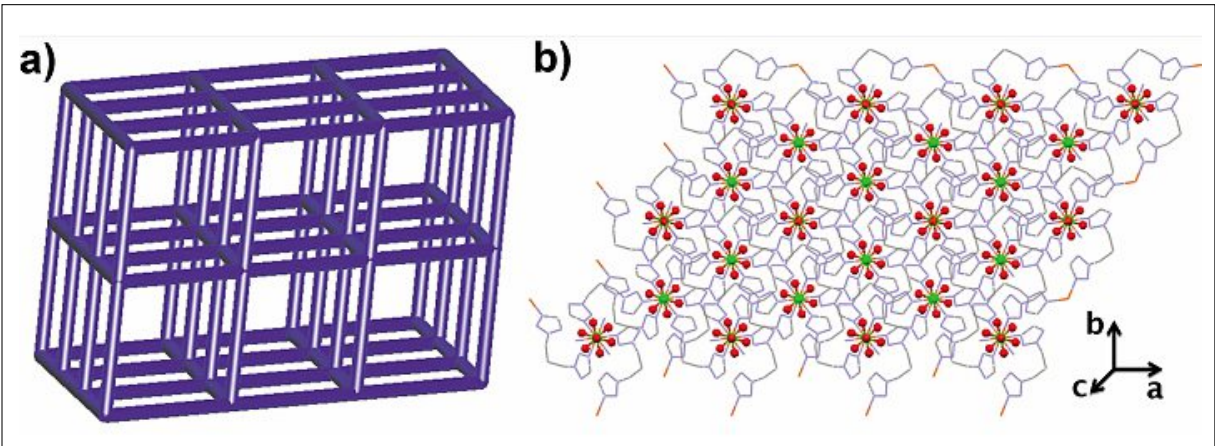

Fig. 11. a) TOPOS ${ }^{[50]}$ view of the 3D coordination polymeric network of 9 with a pcu alpha-Po primitive cubic topology; b) overall packing of $\mathbf{9}$ displaying the perchlorate counter anion (red-green) occupying the voids. ${ }^{[64]}$
This material presents a smooth spin conversion on cooling, ${ }^{[64]}$ again caused by the flexibility of the spacer between tetrazole molecules. Interestingly, the non-solvated material shows a similar crystal structure but retains a HS ground state.

A 3D coordination network constructed from two interlocked cube units was observed for the complexes [Fe(baztrz) $)_{3}$ $\mathrm{A}_{2} \cdot 2 \mathrm{H}_{2} \mathrm{O}\left(\mathrm{A}=\mathrm{ClO}_{4}^{-}, \mathrm{BF}_{4}^{-}\right)$(see Fig. $13 \mathrm{e}$ below) that both display an abrupt transition around room temperature. ${ }^{[52]}$ Such an interlocked architecture was first reported for the 3D CPs $\left[\mathrm{Fe}(\mathrm{btzb})_{3}\right] \mathrm{A}_{2} \cdot \operatorname{Solv},(\mathrm{A}=$ $\mathrm{ClO}_{4}^{-}, \mathrm{PF}_{6}^{-}$; Solv $\left.=\mathrm{MeOH}, \mathrm{H}_{2} \mathrm{O}\right)(\mathrm{btzb}$ 

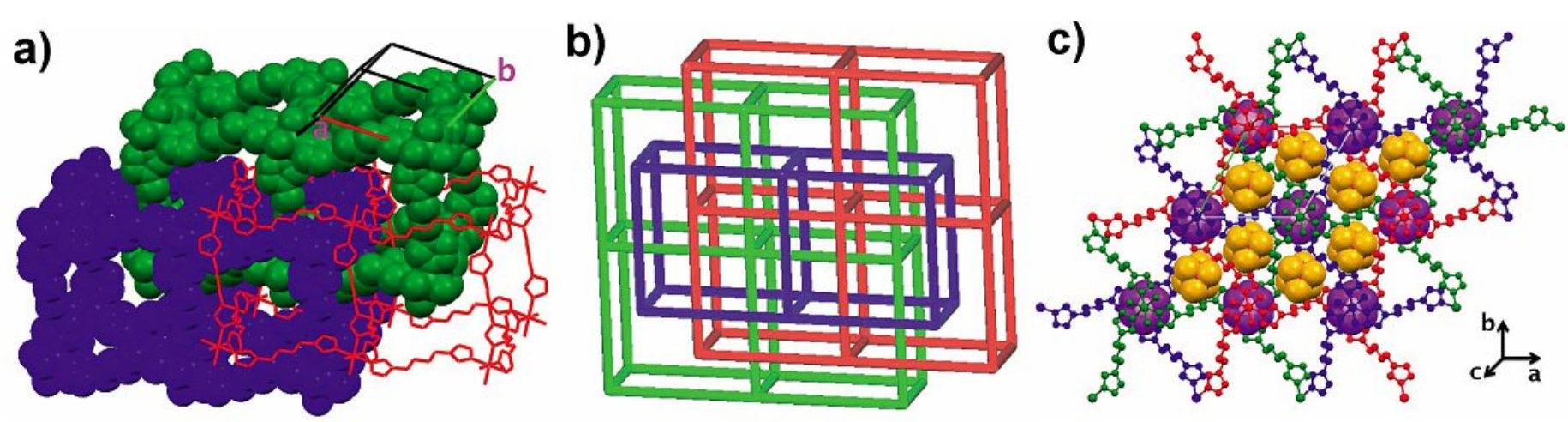

Fig. 12. a) 3D 3-fold interlocked coordination network in $\left[\mathrm{Fe}(\mathrm{btzb})_{3}\right]\left(\mathrm{PF}_{6}\right)_{2}$ (three distinct networks are shown with red, green and blue color); b) TOPOS $^{[50]}$ schematic representation of the interpenetration; $\left.c\right)$ overall packing of $\left[\mathrm{Fe}(\mathrm{btzb})_{3}\right]\left(\mathrm{PF}_{6}\right)_{2}$ displaying the counter anion $\mathrm{PF}_{6}{ }^{-}($orange, spacefill model) and solvent occupying the voids. ${ }^{[65]}$

$=1,2$-bis(tetrazole-1-yl)butane) but with three networks (Fig. 12a,b). ${ }^{[65]}$

An abrupt SCO behavior was observed in contrast to the $3 \mathrm{D}$ bis-tetrazolate $\mathrm{SCO}$ polymer $\left[\mathrm{Fe}_{2}\left(\mathrm{H}_{0.67} \mathrm{bdt}\right)_{3}\right] \cdot 13 \mathrm{H}_{2} \mathrm{O}$ with $\mathrm{H}_{2} \mathrm{bdt}$ $=5,5^{\prime}$-(1,4-phenylene)bis $(1 \mathrm{H}$-tetrazole $)$, which shows a smooth and incomplete spin conversion on cooling below room temperature.[66] Another bidentate ligand based on a pyridine-conjugated Schiff base, afforded a $\mathrm{CP}$ with a diamond-like 3D network made of $\mathrm{FeN}_{4} \mathrm{O}_{2}$ chromophores and displaying a gradual spin conversion. [67] The effect of lattice solvent release on SCO architecture was elegantly investigated on a 3D network constructed from a $1 \mathrm{D}$ chain of formula [ $\mathrm{Fe}(\mu$-baztrz $\left.)(\text { baztrz })_{2}\left(\mathrm{H}_{2} \mathrm{O}\right)_{2}\right]$ $\left(\mathrm{BF}_{4}\right)_{2} \cdot 4 \mathrm{H}_{2} \mathrm{O}(\mathbf{1 0}) .^{[68]}$ In this complex, the equatorial positions of the $\mathrm{Fe}^{\mathrm{II}}$ coordination sphere are partly filled by water molecules (thus setting a $\mathrm{FeN}_{4} \mathrm{O}_{2}$ chromophore) which prevent any switching due to the weak ligand field strength they impose (Fig. 13a). Such 1D chains are further packed in a parallel fashion displaying excellent interdigitation (Fig. 13b) sustained by various intermolecular interactions involving the $\mathrm{BF}_{4}^{-}$counter anion, lattice included and metal bound water molecules (Fig. 13b). Dehydration of $\mathbf{1 0}$ resulted in a new 3D twofold interpenetrated $\mathrm{CP}$ namely $\left[\mathrm{Fe}(\mu \text {-baztrz })_{3}\right]\left(\mathrm{BF}_{4}\right)_{2}(\mathbf{1 1})^{[52]}($ Fig. $13 \mathrm{~d}, \mathrm{e})$; the primary building unit of the $\mathrm{CP}$ is a 'cube' like unit (Fig. 13c) which further extends to form a 3D network having a $\mathrm{FeN}_{6}$ chromophore in which all the six octahedral sites of $\mathrm{Fe}^{\mathrm{II}}$ are occupied with $\mathrm{N}$ atom of bztrz and such networks are then interlocked with the adjacent networks leading to 2-fold interpenetration (Fig. 13d and 13e). The interpenetrated networks recognize each other via various intermolecular interactions involving the counteranion $\mathrm{BF}_{4}^{-}$(Fig. 13f). Interestingly 11 exhibits an abrupt ST at 288 K. ${ }^{[68]}$

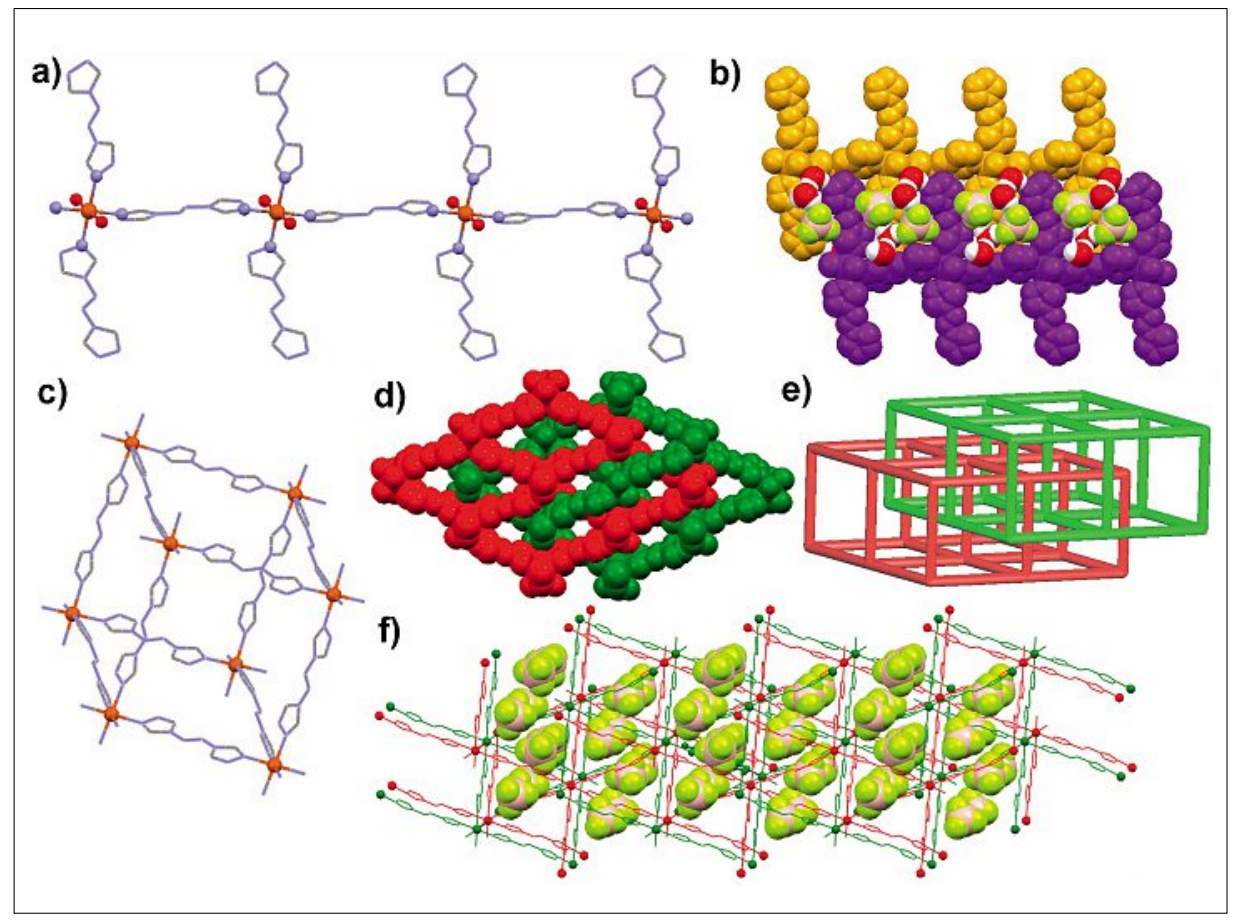

Fig. 13. a) $1 \mathrm{D}$ chain in $\mathbf{1 0}$ displaying the $\mathrm{Fe}^{\| l}$ coordination geometry as $\mathrm{FeN}_{4} \mathrm{O}_{2}$; b) Interdigitated chains in $\mathbf{1 0}$ (shown in orange and purple colour) sustained by various intermolecular interactions involving $\mathrm{BF}_{4}^{-}$and lattice included water molecule (red-white); c) primary building unit of 3D CP 11. ${ }^{[52]} \mathrm{d}$ ) side view of the interpenetrated $3 D$ networks in 11. e) TOPOS ${ }^{[50]}$ diagram of the interpenetrated network in 11; f) Overall packing of the interpenetrated networks and occluded guests $\mathrm{BF}_{4}^{-}$(shown in spacefill model) - (distinct networks are displayed with red and green).

\section{Concluding Remarks}

Spin crossover coordination polymers derived from triazole/tetrazole ligands and the factors affecting their resultant magnetic property have been highlighted in this review. We have outlined for 1D chains, the importance of having both a rigid linker between spin centers of $\mathrm{FeN}_{6}$ nature with an appropriate ligand field, and a dense supramolecular network in their crystal lattice to facilitate SCO cooperativity. The functional group (-R) present in the triazole/tetrazole ligands can indeed produce steric, $\pi$ stacking, H-bonding effects and other weak interactions between the chains, which can influence spin crossover cooperativity.

New rigid ligands containing predesigned modules suitable for supramolecular contacts will be designed to enhance general knowledge on this family of switchable materials. Besides, in 2D and $3 \mathrm{D}$ coordination polymers the relevance of keeping a subtle balance between flexibility and rigidity of the crystal lattice without neglecting supramolecular contacts, has been highlighted. We trust that many more examples of poly-azole coordination polymers ${ }^{[69]}$ will be synthesized, particularly based on bis-1,2,4-triazoles after the communication of a revised one-step syn- 
thesis of 1,2,4-triazole derivatives thanks to a simplified transamination method reducing reaction time, increasing yield and avoiding tedious chromatographic separations. ${ }^{[70]}$ More $\mathrm{Fe}^{\mathrm{II}}$ bis-tetrazole coordination networks are also expected following novel synthetic routes. ${ }^{[71]}$ The synthesis of asymmetric ligands containing a tetrazole as well as a 1,2,4-triazole, ,72,73] or 1,2,3-triazole $^{[74]}$ has just started and already afforded interesting coordination polymers, which are expected to reveal multistep spin crossover. ${ }^{[74]}$ The switching properties along with the associated pronounced color of these materials are attractive considering their application as thermal and pressure sensors or optical devices.

\section{Acknowledgment}

We thank the Fonds National de la Recherche Scientifique-FNRS (FRFC 2.4508.08) and the COST action MP1202 'Rational design of hybrid organic-inorganic interfaces: the next step towards advanced functional materials'. N. N. Adarsh is holder of research stipendium from the Federal science policy, cofunded by Marie Curie actions of the European Commission.

\section{Received: February 20, 2013}

[1] a) C. Janiak, Dalton Trans. 2003, 2781; b) A. Y. Robin, K. M. Fromm, Coord. Chem. Rev. 2006, 250, 2127; c) S. R. Batten, S. M. Neville, D. R. Turner, 'Coordination Polymers: Design, Analysis and Application', RSC 2009, Cambridge; d) A. D. Naik, M. M. Dîrtu, A. P. Railliet, J. Marchand-Brynaert, Y. Garcia, Polymers 2011, 3, 1750; e) E. C. Constable, in 'Molecules to Nanomaterials', Eds. J. W. Steed, P. A. Gale, John Wiley \& Sons Ltd, Chichester, UK, 2012, p. 3073; f) N. N. Adarsh, P. Dastidar, Chem. Soc. Rev. 2012, 41, 3039.

[2] a) M. O'Keeffe, O. M. Yaghi, Chem. Rev. 2012, 112,675 ; b) T. Uemura, N. Yanai, S. Kitagawa, Chem. Soc. Rev. 2009, 38, 1228; c) L. R. MacGillivray, 'Metal-Organic Frameworks: Design and Application', John Wiley \& Sons 2010; d) S. M. Cohen, Chem. Rev. 2012, 112, 970; d) Y. Cui, Y. Yue, G. Qian, B. Chen, Chem. Rev. 2012, 112, 1126; e) G. Férey, Chem. Soc. Rev. 2008, 37, 191; f) T. R. Cook, Y.-R. Zheng, P. J. Stang, Chem. Rev. 2013, 113, 734 .

[3] J. W. Steed, J. L. Atwood, 'Supramolecular Chemistry', John Wiley \& Sons, Chichester, 2nd edn, 2009.

[4] G. R. Desiraju, J. J. Vittal, A. Ramanan, 'Crystal Engineering - A Textbook', World Scientific, 2011.

[5] M. Fukuya, M. Ohba, K.-I. Motoda, N Matsumoto, H. Ôkawa, Y. Maeda, J. Chem. Soc., Dalton Trans. 1993, 3277.

[6] S. Imatomi, R. Kitashima, T. Hamamastu, M. Okeda, Y. Ogawa, M. Matsumoto, Chem. Lett. 2006, 35,502 .

[7] S. Hayami, K. Hashiguchi, G. Juhasz, M. Ohba, H. Okawa, Y. Maeda, K. Kato, K. Osaka, M. Takata, K. Inoue, Inorg. Chem. 2004, 43, 4124

[8] K. Bhar, S. Khan, J. S. Costa, J. Ribas, O. Roubeau, P. Mitra, B. K. Ghosh, Angew. Chem., Int. Ed. 2012, 51, 2142.

[9] a) J. A. Real, A. B. Gaspar, V. Niel, M. C. Muñoz, Coord. Chem. Rev. 2003, 236, 121; b) J. A. Real, A. B. Gaspar, M. C. Muñoz. Dalton Trans. 2005, 2062; c) M. C. Muñoz, J. A. Real,
Coord. Chem. Rev. 2011, 255, 2068; d) B. Weber, Coord. Chem. Rev. 2009, 253, 2432 ; e) B. Weber, Möss. Eff. Ref. Data J. 2012, 35, 239; f) K. S. Murray, Eur. J. Inorg. Chem. 2008, 3101 .

[10] P. Gütlich, A. B. Gaspar, Y. Garcia, Belstein J. Org. Chem. 2013, 9, 342; and references therein.

[11] a) O. Kahn, C. J. Martinez, Science 1998, 279, 44; b) Y. Garcia, V. Ksenofontov, P. Gütlich, Hyperfine Interact. 2002, 139/140, 543; c) J. Linares, E. Codjovi, Y. Garcia, Sensors 2012, $12,4479$.

[12] O. Kahn, J. Kröber, C. Jay, Adv. Mater. 1992, 4, 718.

[13] O. Roubeau, Chem. Eur. J. 2012, 18, 15230.

[14] a) A. Michalowicz, J. Moscovici, B. Ducourant, D. Cracco, O. Kahn. Chem. Mater. 1995, 7, 1833; b) Y. Garcia, P. J. van Koningsbruggen, G. Bravic, P. Guionneau, D. Chasseau, G. L. Cascarano, J. Moscovici, K. Lambert, A. Michalowicz, O. Kahn. Inorg. Chem. 1997, 36, 6357; c) T. Yokoyama, Y. Murakami, M. Kiguchi, T. Komatsu, N. Kojima. Phys. Rev. B. 1998, 58, 14238; d) A. Michalowicz, J. Moscovici, Y. Garcia, O. Kahn. J. Synchrotron Rad. 1999, 6, 231; e) S. B. Erenburg, N. V. Bausk, L. G. Lavrenova, L. N. Mazalov. $J$. Magn. Magn. Mater. 2001, 226, 1967; f) A. Michalowicz, J. Moscovici, J. Charton, F. Sandid, F. Benamrane, Y. Garcia. J. Synchrotron Rad. 2001, 8, 701.

[15] A. Grosjean, N. Daro, B. Kauffman, A. Kaiba, J.-F. Létard, P. Guionneau, Chem. Commun. 2011, 47, 12382.

[16] J. Kröber, E. Codjovi, O. Kahn, F. Groliere, C. Jay, J. Am. Chem. Soc. 1993, 115, 9810.

[17] Y. Garcia, V. Niel, M. C. Muñoz, J. A. Real, Top. Curr. Chem. 2004, 233, 229.

[18] J. G. Haasnoot, G. Vos, W. L. Groeneveld, Z. Naturforsch. 1977, 32b, 1421.

[19] J. Kröber, J. P. Audiere, R. Claude, E. Codjovi, O. Kahn, J. G. Haasnoot, F. Groliere, C. Jay, A. Bousseksou, J. Linares, F.Varret, A. Gonthiervassal, Chem. Mater. 1994, 6, 1404.

[20] M. Verelst, L. Sommier, P. Lecante, A. Mosset, O. Kahn, Chem.Mater. 1998, 10, 980.

[21] A. Grosjean, P. Négrier, P. Bordet, C. Etrillard, D. Mondieig, S. Pechev, E. Lebraud, J.-F. Létard, P. Guionneau, Eur. J. Inorg. Chem. 2013, 796.

[22] Y. Garcia, J. Moscovici, A. Michalowicz, V. Ksenofontov, G. Levchenko, G. Bravic, D. Chasseau, P. Gutlich, Chem. Eur. J. 2002, 8 , 4992.

[23] L. G. Lavrenova, V. N. Ikorskii, V. A. Varnek, I. M. Oglezneva, S. V. Larionov, Koord. Khim. 1986, 12, 207.

[24] M. M. Dîrtu, C. Neuhausen, A. D. Naik, A. Rotaru, L. Spinu, Y. Garcia, Inorg. Chem. 2010, 49, 5723.

[25] Y. Garcia, S. J. Campbell, J. S. Lord, Y. Boland, V. Ksenofontov, P. Gütlich, J. Phys. Chem. B 2007, 111, 11111 .

[26] P. J. van Koningsbruggen, Y. Garcia, O. Kahn, H. Kooijman, A. L. Spek, J. G. Haasnoot, J. Moscovici, K. Provost, A. Michalowicz, L. Fournès, F. Renz, P. Gütlich, Inorg. Chem. 2000, 39, 1891.

[27] S. Decurtins, P. Gütlich, C. P. Köhler, H. Spiering, A. Hauser, Chem. Phys. Lett. 1984, 105,1

[28] J. Schweifer, P. Weinberger, K. Mereiter, M. Boca, C. Reichl, G. Wiesinger, G. Hilscher, P. J. van Koningsbruggen, H. Kooijman, M. Grunert, W. Linert, Inorg. Chim. Acta 2002, 339, 297.

[29] M. Quesada, F. Prins, E. Bill, H. Kooijman, P. Gamez, O. Roubeau, A. L. Spek, J. G. Haasnoot, J. Reedijk, Chem. Eur. J. 2008, 14, 8486.

[30] A. Bialonska, R Bronisz, M. Weselski, Inorg. Chem. 2008, 47, 4436.

[31] M. Quesada, H. Kooijman, P. Gamez, J. Sanchez
Costa, P. J. van Koningsbruggen, P. Weinberger, M. Reissner, A. L. Spek, J. G. Haasnoot, J. Reedijk, Dalton. Trans. 2007, 5434.

[32] D. Müller, C. Knoll, B. Stöger, W. Artner, M. Reissner, P. Weinberger, Eur. J. Inorg. Chem. 2013, 984.

[33] P. J. van Konginsbruggen, Top. Curr. Chem. 2004, 233, 123.

[34] A. Galet, M. C. Muñoz, J. A. Real, Inorg. Chem. 2006, 45, 4583.

[35] a) F.-L. Yang, B. Li, T. Hanajima, Y. Einaga, R.B. Huang, L.-S. Zheng, J. Tao, Dalton Trans. 2010, 39, 2288; b) F.-L. Yang, J. Tao, R.-B. Huang, L.-S. Zheng, Inorg. Chem. 2011, 50, 911.

[36] T. M. Ross, B. Moubaraki, S. R. Batten, K. S. Murray, Dalton Trans. 2012, 41, 2571.

[37] A. Białońska, R. Bronisz, L. Baranowski, Eur. J. Inorg. Chem. 2013, 720.

[38] G. S. Matouzenko, M. Perrin, B. Le Guennic, C. Genre, G. Molnár, A. Bousseksou, S. A. Borshch, Dalton Trans. 2007, 7, 934.

[39] a) G. S. Matouzenko, G. Molnar, N. Bréfuel, M. Perrin, A. Bousseksou, S. A. Borshch, Chem. Mater. 2003, 15, 550; b) C. Genre, G. S. Matouzenko, E. Jeanneau, D. Luneau, New J. Chem. 2006, 30, 1669.

[40] a) S. M. Neville, B. A. Leita, D. A. Offermann, M. B. Duriska, B. Moubaraki, K. Chapman, G. J. Halder, K. S. Murray, Eur. J. Inorg. Chem. 2007, 1073; b) T. M. Ross, B. Moubaraki, D. R. Turner, G. J. Halder, G. Chastanet, S. M. Neville, J. D. Cashion, J.-F. Létard, S. R. Batten, K. S. Murray, Eur. J. Inorg. Chem. 2011, 1395; c) S. M. Neville, B. A. Leita, G. J. Halder, C. J. Kepert, B. Moubaraki, J.-F. Létard, K. S. Murray, Chem. Eur. J. 2008, 14, 10123.

[41] A. Bialonska, R. Bronisz, K. Darowska, K. Drabent, J. Kusz, M. Siczek, M. Weselski, M. Zubko, A. Ozarowski, Inorg. Chem. 2010, 49, 11267.

[42] C. Genre, E. Jeanneau, A. Bousseksou, D. Luneau, S. A. Borshch, G. S. Matouzenko, Chem. Eur. J. 2008, 14, 697.

[43] G. Dupouy, S. Triki, M. Marchivie, N. Cosquer, C. J. Gomez-Garcia, S. Pillet, el-E. Bendeif, C. Lecomte, S. Asthana, J.-F. Létard, Inorg. Chem. 2010, 49, 9358.

[44] P. Gütlich, Y. Garcia, H. Spiering, in 'Magnetism: Molecules to Materials IV', Eds. J. S. Miller, M. Drillon, Wiley-VCH Verlag: Weinheim, 2003, p. 271.

[45] J.-P. Zhang, Y.-B. Zhang, J.-B. Lin, X.-M. Chen, Chem. Rev. 2012, 112, 1001.

[46] M. C. Muñoz, J. A. Real, Coord. Chem. Rev. 2011, 255, 2068.

[47] W. Vreugdenhil, J. H. van Diemen, R. A. G. de Graaff, J. G. Haasnoot, J. Reedijk, A. M. van der Kraan, O. Kahn, J. Zarembowitch, Polyhedron 1990, 9, 2971.

[48] A. Ozarowski, Y. Shunzhong, B. R. McGarvey, A. Mislankar, J. E. Drake, Inorg. Chem. 1991, 30, 3167 .

[49] a) Y. Garcia, V. Ksenofontov, G. Levchenko, G. Schmitt, P. Gütlich, J. Phys. Chem. B 2000, 21, 5045; b) M.-L. Boillot, J. Zarembowitch, J.-P. Itié, A. Polian, E. Bourdet, J. G. Haasnoot, New J. Chem. 2002, 26, 313.

[50] V. A. Blatov, D. M. Proserpio, TOPOS 4.0, A Program Package for Multipurpose Crystallochemical Analysis, www.topos.ssu. samara.ru/.

[51] Y. Garcia, G. Bravic, D. Chasseau, C. Gieck, W. Tremel, P. Gütlich, Inorg. Chem. 2005, 44, 9723.

[52] Y.-C. Chuang, C.-T. Liu, C.-F. Sheu, W.-L. Ho, G.-H. Lee, C.-C. Wang, Y. Wang, Inorg. Chem. 2012, 51, 4663.

[53] A. Bialonska, R. Bronisz, Inorg. Chem. 2010, 49, 4534.

[54] M. Quesada, F. Prins, O. Roubeau, P. Gamez, S. J. Teat, P. J. van Koningsbruggen, J. G. 
Haasnoot, J. Reedijk, Inorg. Chim. Acta 2007, $360,3787$.

[55] a) R. Bronisz, Z. Ciunik, K. Drabent, M. F. Rudolf, Conf. Proc., ICAME-95, 1996, 50, 15; b) R. Bronisz, Ph. D. Thesis, University of Wroclaw, Poland, 1999.

[56] A. Bialonska, R. Bronisz, M. F. Rudolf, M. Weselski, Inorg. Chem. 2012, 51, 237.

[57] Y. Boland, P. Herstens, J. Marchand-Brynaert, Y. Garcia, Synthesis 2006, 9, 1504.

[58] R. Bronisz, Inorg. Chem. 2005, 44, 4463.

[59] J. Kusz, R. Bronisz, M. Zubko, G. Bednarek, Chem. Eur. J. 2011, 17, 6807.

[60] P. Chakraborty, R. Bronisz, C. Besnard, L. Guénée, P. Pattison, A. Hauser, J. Am. Chem. Soc. 2012, 134, 4049.

[61] a) I. Krivokapic, C. Enachescu, R. Bronisz, A. Hauser, Chem. Phys. Lett. 2008, 455, 192; b) I. Krivokapic, C. Enachescu, R. Bronisz, A. Hauser, Inorg. Chim. Acta 2008, 361, 3616; c) C. Chong, A. Slimani, F. Varret, K. Boukheddaden, E. Collet, J.-C. Ameline, R. Bronisz, A. Hauser, Chem. Phys. Lett. 2011, 504, 29.
[62] X. Bao, P.-H. Guo, W. Liu, J. Tucek, W.-W. Zhang, J.-D. Leng, X.-M. Chen, I. Gural'skiy, L. Salmon, A. Bousseksou, M.-L. Tong, Chem. Sci. 2012, 3, 1629.

[63] Y. Garcia, O. Kahn, L. Rabardel, B. Chansou, L. Salmon, J.-P. Tuchagues, Inorg. Chem. 1999, $38,4663$.

[64] R. Bronisz, Inorg. Chem. 2007, 46, 6733.

[65] a) P. J. van Koningsbruggen, Y. Garcia, H. Kooijman, A. L. Spek, J. G. Haasnoot, O. Kahn, J. Linares, E. Codjovi, F. Varret, Dalton. Trans. 2001, 466; b) C. M. Grunert, J. Schweifer, P. Weinberger, W. Linert, K. Mereiter, G. Hilscher, M. Muller, G. Wiesinger, P. J. van Koningsbruggen, Inorg. Chem. 2004, 43, 155; c) M. Bartel, A. Absmeier, G. N. L. Jameson, F. Werner, K. Kato, M. Takata, R. Boca, M. Hasegawa, K. Mereiter, A Caneschi, W. Linert, Inorg. Chem. 2007, 46, 4220.

[66] a) W.-T. Liu, J.-Y. Li, Z.-P. Ni, X. Bao, Y.-C. Ou, J.-D. Leng, J.-L. Liu, M.-L. Tong, Crystal Growth Des. 2012, 12, 1482; b) Z. Yan, M. Li,
H.-L. Gao, X.-C. Huang, D. Li, Chem. Comm. 2012, 48, 3960

[67] L. Li, G. J. Clarkson, D. J. Evans, M. R. Lees, S. S. Turner, P. Scott, Chem. Commun. 2011, 47, 12646.

[68] Y.-C. Chuang, W.-L. Ho, C.-F. Sheu, G.-H. Lee, Y. Wang, Chem. Commun. 2012, 48, 10769.

[69] G. Aromi, L. Barrios, O. Roubeau, P. Gamez, Coord. Chem. Rev. 2011, 255, 485.

[70] A. D. Naik, J. Marchand-Bryanert, Y. Garcia, Synthesis 2008, 1, 149.

[71] a) A. Białońska, R. Bronisz, Tetrahedron 2008, 64,9771 ; b) Y. Boland, D. A. Safin, B. Tinant, M. G. Babashkina, J. Marchand-Brynaert, Y. Garcia, New J. Chem. 2013, 37,1174.

[72] Y. Boland, B. Tinant, D. A. Safin, J. MarchandBrynaert, R. Clérac, Y. Garcia, CrystEngComm. 2012, 14, 8153.

[73] A. D. Naik, A. P. Railliet, M. M. Dîrtu, Y. Garcia, Hyperfine Interact. 2012, 204, 119.

[74] A. Białońska, R. Bronisz, J. Kusz, M. Zubko, Eur. J. Inorg. Chem. 2013, 884. 